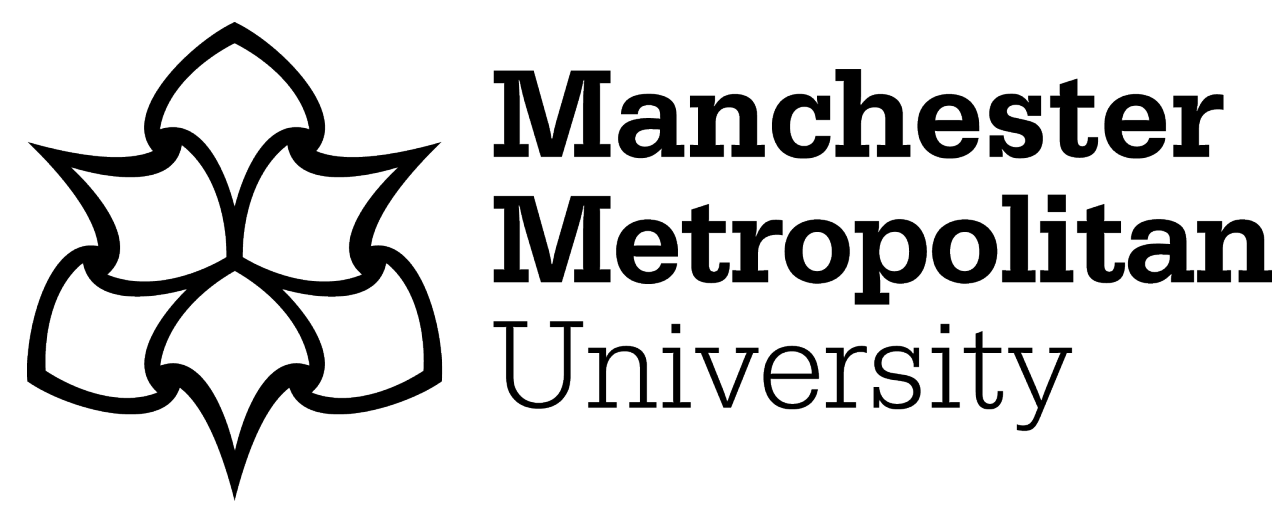

Thomas, C, Comfort, P, Jones, PA and Dos'Santos, T (2017) A comparison of isometric midthigh-pull strength, vertical jump, sprint speed, and change-ofdirection speed in academy netball players. International Journal of Sports Physiology and Performance, 12 (7). pp. 916-921. ISSN 1555-0265

Downloaded from: https://e-space.mmu.ac.uk/626036/

Version: Accepted Version

Publisher: Human Kinetics

DOI: https://doi.org/10.1123/ijspp.2016-0317

Please cite the published version 


\title{
A Comparison of Isometric Midthigh-Pull Strength, Vertical Jump, Sprint Speed, and Change-of-Direction Speed in Academy Netball Players
}

\author{
Christopher Thomas, Paul Comfort, Paul A. Jones, and Thomas Dos'Santos
}

\begin{abstract}
Purpose: To investigate the relationships between maximal isometric strength, vertical jump (VJ), sprint speed, and changeof-direction speed (CoDS) in academy netball players and determine whether players who have high performance in isometric strength testing would demonstrate superior performance in VJ, sprint speed, and CoDS measures. Method: Twenty-six young female netball players (age $16.1 \pm 1.2 \mathrm{y}$, height $173.9 \pm 5.7 \mathrm{~cm}$, body mass $66.0 \pm 7.2 \mathrm{~kg}$ ) from a regional netball academy performed isometric midthigh pull (IMTP), squat jumps (SJs), countermovement jumps (CMJs), 10-m sprints, and CoDS (505). Results: IMTP measures displayed moderate to strong correlations with sprint and CoDS performance $(r=-.41$ to -.66$)$. The VJs, which included SJs and CMJs, demonstrated strong correlations with $10-\mathrm{m}$ sprint times $(r=-.60$ to $-.65 ; P<.01)$ and CoDS $(r=-.60$ to $-.71 ; P=.01)$. Stronger players displayed significantly faster sprint $(\mathrm{ES}=1.1-1.2)$ and $\mathrm{CoDS}$ times $(\mathrm{ES}=$ 1.2-1.7) and greater VJ height $(\mathrm{ES}=0.9-1.0)$ than weaker players. Conclusion: The results of this study illustrate the importance of developing high levels of lower-body strength to enhance VJ, sprint, and CoDS performance in youth netball players, with stronger athletes demonstrating superior VJ, sprint, and CoDS performances.
\end{abstract}

Keywords: short-sprint performance, acceleration, maximal isometric strength, dynamic performance

Previous literature indicates that isometric measures of maximum strength have strong correlations with dynamic exercise variables in adult athletes. ${ }^{1-4}$ However, there is very limited research in the area of maximum strength, vertical jump (VJ), sprint, and change-of-direction speed (CoDS) in youth netball athletes. ${ }^{2}$ Several of the characteristics associated with maximum isometric strength (peak force $[\mathrm{PF}]$ and rate of force development) have been reported to relate to athletic performance tasks such as $\mathrm{VJ},{ }^{5} \mathrm{CoDS},{ }^{6}$ and sprinting. ${ }^{4}$ The isometric midthigh pull (IMTP) is commonly used to test maximum force-production capabilities in a range of athletes. ${ }^{2-4}$ The IMTP translates to a variety of sports, is easy to replicate, and is a time-efficient method of maximum-strength assessment. Furthermore, the isometric testing may induce less neuromuscular fatigue than dynamic 1-repetition-maximum testing. ${ }^{7}$ Therefore, the IMTP may be used to assess talent identification and athlete preparedness, monitor the effectiveness of training interventions, and compare athletes' isometric-force capabilities against their dynamic-force capability. ${ }^{8}$

Activity profiles of international netball suggest that all players are constantly performing high-intensity movement patterns (shuffling, running, sprinting, jumping), ${ }^{9}$ requiring near-maximum levels of muscle strength and power production. ${ }^{10}$ This may be explained by the fact that peak ground-reaction forces and impulse are strong determinants of VJ, sprint, and CoDS performance. ${ }^{3,11}$ Also, training-induced increases in measures of maximum strength have been shown to result in improved VJ, sprint, and CoDS performance. ${ }^{12,13}$

The countermovement jump (CMJ) and squat jump (SJ) are commonly used VJ field tests to assess lower-body explosive perfor-

The authors are with the Directorate of Sport, Exercise and Physiotherapy, University of Salford, Salford, Greater Manchester, UK. Thomas (C.Thomas2@edu.salford.ac.uk) is corresponding author. mance. However, it should be noted that CMJ and SJ are not direct measures of lower-body power; rather, jump height is a measurable result of lower-body power production that is highly applicable to performance in many sports and serves as a practical, cost-effective field assessment for sport scientists and practitioners. Previous research shows significant associations between CMJ and SJ and sprint performance. ${ }^{14}$ Likewise, Peterson et $\mathrm{al}^{15}$ found CMJ height derived from a jump-and-reach apparatus to significantly correlate $(r$ $=-.71$ ) with CoDS in first-year female college athletes. Furthermore, CMJ height has shown significant and inverse moderate to strong relationships ( $r=-.39$ to -.59 ) with 505 CoDS in university students when calculated from flight time using jump mats. ${ }^{16}$ Thus, assessing VJ performance may be of particular interest to prescribe and monitor the training of athletes to create an accurate player profile.

The aim of this study was to determine the relationships between maximal isometric strength, $\mathrm{VJ}$, sprint, and CoDS in academy netball players. In addition, observations were made to discover whether players who have high performance in IMTP would demonstrate superior performance in VJ, sprint, and CoDS measures. We hypothesized that relationships between maximal isometric strength and VJ, sprint, and CoDS would be similar to those previously identified.,3 Furthermore, we hypothesized that relatively stronger players would perform better in VJ, sprint, and CoDS measures than weaker players.

\section{Methods}

\section{Subjects}

Young female netball players $(\mathrm{N}=26$; age $16.1 \pm 1.2 \mathrm{y}$, height 173.9 $\pm 5.7 \mathrm{~cm}$, body mass $66.0 \pm 7.2 \mathrm{~kg}$ ) participated in this study. All provided written informed consent, with consent from the parent or 
guardian of all players under the age of 18 . The study procedures were approved by the university ethics committee, and procedures conformed to the Declaration of Helsinki.

\section{Design}

A cross-sectional design was used to investigate the relationships between isometric strength (IMTP PF), VJ (SJ and CMJ height), sprint speed (5 and $10 \mathrm{~m}$ ), and CoDS (505) in academy netball players. Moreover, comparisons of the strongest and weakest athletes were performed to assist in confirming the primary findings of the study.

\section{Procedures}

Testing was conducted in the preseason, during which time all participants were training with sessions comprising all the elements of performance, including 4 or 5 netball-specific training sessions, plus 2 resistance-training sessions each week. At the time of testing, participants were at the end of a 4-week general-preparation mesocycle.

Participants attended testing on 2 separate occasions, at the same time of day, to undertake IMTP testing on day 1, with VJ, sprint, and CoDS performance measures completed on day 2, separated by 48 to 72 hours. On arrival, all participants had their height (Stadiometer; Seca, Birmingham, UK) and body mass assessed (Seca Digital Scales, Model 707) while in bare feet, measured to the nearest $0.1 \mathrm{~kg}$ and $0.1 \mathrm{~cm}$, respectively. All athletes rested the day before testing and were asked to attend testing in a fed and hydrated state, similar to their normal practices before training. Before the start of testing, athletes were instructed to perform a standardized warm-up, as directed by the investigator. Furthermore, standardized progressive warm-ups were applied before all tests to control potential variables and improve the reliability of all tests.

\section{Isometric Midthigh-Pull Testing}

IMTP was performed using a portable force platform sampling at 600 Hz (400 Series Performance Force Plate; Fitness Technology). The force platform was interfaced with computer software (BMS) that allows for direct measurement of force-time characteristics that were then analyzed using the BMS software. For the IMTP, athletes obtained self-selected knee and hip angles based on the reports of previous research. ${ }^{17}$ For this test, an immovable, collarless steel bar was positioned at midthigh, just below the crease of the hip, using a portable IMTP rig (Fitness Technology, Adelaide, Australia). The bar height could be adjusted (3-cm increments) at various heights above the force platform to accommodate different-size athletes. Once the bar height was established, the athlete stood on the force platform and her hands were strapped to the bar in accordance with previously established methods. ${ }^{18}$ Each athlete was provided 2 warm-up pulls, 1 at $50 \%$ and 1 at $75 \%$ of her perceived maximum effort, separated by 1 minute of rest. Once body position was stabilized (verified by watching the subject and force trace), the subject was given a countdown of " 3,2 , 1, pull." Minimal pre-tension was allowed to ensure that there was no slack in the subject's body before initiation of the pull. Athletes performed 3 maximal IMTPs, with the instruction to pull against the bar with maximal effort as quickly as possible and push the feet down into the force platform; this instruction has been previously found to produce optimal testing results. ${ }^{18}$ Each maximal isometric trial was performed for 5 seconds, and all athletes were given strong verbal encouragement during each trial. Two minutes of rest were given between the maximal-effort pulls. The maximum force recorded from the force-time curve during the 5-second IMTP trial was reported as the PF and was presented as a value relative to body mass $(\mathrm{N} / \mathrm{kg})$. The best performance from each of the 3 trials was used for further analysis.

\section{VJ Testing}

VJ-height data were collected using a portable jump mat (Just Jump; Probiotics, Huntsville, AL, USA). The athletes were familiar with all jumps and explosive exercise, permitting the use of warm-up sets for familiarization with the equipment to ensure reliable jump performances. VJ tests began with the SJ condition. On stepping onto the jump mat, athletes were instructed to get in the "ready position," which consisted of the subject having her hands on hips and assuming a self-selected squat depth. Once in position, a countdown of "3, 2, 1 jump" was given. A 3-second hold of the bottom position was used to eliminate the involvement of the stretch-shortening cycle. If players failed to adhere to the strict protocol and either performed a countermovement or moved their hands off their hips, the trial was repeated after an additional 1-minute rest. Athletes performed 3 trials with 1 minute of rest between trials. On completion of the SJ trials, athletes were provided with a rest period of 3 minutes before performing the CMJ trials. For the CMJ, athletes were instructed to perform a rapid eccentric phase, immediately followed by a rapid concentric phase with the intention to jump as high as possible. CMJs were performed with the hands on the hips, and countermovement depth of the eccentric phase was self-selected by the athletes to maximize CMJ height. Athletes performed 3 trials, with 1 minute of rest between trials. Alternate jump height was calculated from flight time $\left(1 / 8\left[g \times t^{2}\right]\right.$, where $g=$ the acceleration due to gravity and $t=$ air time) and subsequently corrected with the following equation: jump height $=(0.8747 \times$ alternative jump height) $-0.0666 .{ }^{19}$ The best performance from each of the 3 trials was used for further analysis.

\section{Sprint and CoDS Testing}

The 10-m-sprint test was administered as a test of acceleration and sprint ability. All athletes performed 3 trials, with 2 minutes rest between trials, using Brower photocell timing gates (model number BRO001; Brower, Draper, UT, USA) set up at 0, 5, and $10 \mathrm{~m}$. Timing gates were placed at the approximate hip height for all athletes, to ensure that only 1 body part, such as the lower torso, broke the beam. Athletes started $0.5 \mathrm{~m}$ behind the first gate to prevent any early triggering of the initial start gate, from a 2-point staggered start. The best performance from each of the 3 trials was used for further analysis.

CoDS was assessed with a 505 test. All athletes performed 3 trials on each leg, in a randomized order, with 2-minute rests between trials. Athletes started $0.5 \mathrm{~m}$ behind the photocell gates to prevent any early triggering of the initial start gate, from a 2-point staggered start. Timing gates were again placed at the approximate hip height for all athletes. Athletes were instructed to sprint to a line marked $15 \mathrm{~m}$ from the start line, place either left or right foot on the line, depending on the trial, turn $180^{\circ}$, and sprint back $5 \mathrm{~m}$ through the finish. If the subject changed direction before hitting the turning line or turned off the incorrect foot, the trial was disregarded and the subject completed another trial after the rest period. The best performance from each of the 3 trials was used for further analysis. 


\section{Statistical Analyses}

Data are presented as either mean \pm SD or mean with $90 \%$ confidence intervals $(90 \% \mathrm{CI})$ where specified. Within-session reliability of dependent variables was examined using the intraclass correlation coefficient (ICC) and typical error of measurement (TE) expressed as a coefficient of variation (CV). ICC, TE, and CV were calculated through an available online spreadsheet. ${ }^{20}$ To assess the magnitude of the ICC, the threshold values were $.1, .3, .5, .7, .9$, and 1.0 for low, moderate, high, very high, nearly perfect, and perfect, respectively. ${ }^{21}$ Normality of data was assessed by Shapiro-Wilk statistic and Q-Q plot analysis. Relationships between variables were determined using Pearson product-moment correlation with SPSS software (version 17.0; SPSS, Inc). Correlations were Bonferroni corrected due to multiple correlations, to reduce the risk of a type 1 error. $^{22}$ Correlations were evaluated as follows: small $(.10-.29)$, moderate $(.30-.49)$, large $(.50-.69)$, very large $(.70-.89)$, nearly perfect $(.90$ $-.99)$, and perfect (1.0). ${ }^{23}$ The criterion for statistical significance of the correlation was set at $P \leq .05$. Additional analysis included comparisons of the strongest to the weakest athletes with respect to IMTP PF (N/kg) only. This additional analysis was performed to assist in confirming the primary findings of the study. Based on IMTP PF, athletes were grouped into the strongest group $(\mathrm{SG} ; \mathrm{n}=$ 13 ) and weakest group (WG; $\mathrm{n}=13$ ). Independent-samples $t$ tests were performed to determine differences in VJ, sprint, and CoDS performances between SG and WG. The criterion for statistical significance was set at $P \leq .05$. The magnitude of differences between $\mathrm{SG}$ and WG mean values was also expressed as standardized mean difference (Cohen effect sizes [ES]). ${ }^{24}$ Effect sizes were classified as trivial $(\leq 0.19)$, small $(0.20$ to 0.59$)$, moderate (0.60 to 1.19$)$, large (1.20 to 1.99$)$, and very large $(2.0$ to 4.0$){ }^{23}$

\section{Results}

Resulting ICCs demonstrated nearly perfect within-session reliability ( $r \geq .91$; CV $=3.5-5.3 \%$ ) for all IMTP and VJ variables, whereas sprint and CoDS performances showed very high levels of reliability $(r=.74-.82 ; \mathrm{CV}=2.1-2.9 \%)$ (Table 1$)$.

Pearson correlations demonstrated moderate to strong inverse correlations ( $r=-.48$ to -.66 ) between IMTP PF and CoDS (Table 2 ) times. In addition, 10-m-sprint time showed strong correlations with 505 CoDS ( $r=-.53$ to -.58 ), whereas 5-m-sprint time demonstrated no correlation to $505 \mathrm{CoDS}(r=.25-.30)$. SJ height showed very large correlations with $505 \operatorname{CoDS}(-.70$ to -.71), whereas CMJ height demonstrated large to very large correlations with $505 \mathrm{CoDS}$ (-.60 to -.71$)$.

Our data show that IMTP PF was significantly correlated to 5-m-sprint times $(r=-.49 ; P=.05)$ but not 10 -m-sprint times $(r$ $=-.41 ; P>.05$ ) (Table 3 ). In addition, SJ and CMJ height demonstrated large inverse relationships with 10-m-sprint times $(r=$ -.60 to $-.65 ; P=.01)$, whereas no significant relationships were found between $\mathrm{SJ}$ and $\mathrm{CMJ}$ height, and 5-m-sprint times $(r=-.13$ to $-.15 ; P>.05)$.

Differences between SG and WG athletes' mean values are presented in Table 4. There was no significant difference in body mass between SG and WG athletes (SG $65.54 \pm 6.90 \mathrm{~kg}$; WG 66.54 $\pm 7.82 ; P=.73 ; \mathrm{ES}=0.1)$. As expected, the $\mathrm{SG}$ had a higher $\mathrm{PF}$ $(34.86 \pm 4.02 \mathrm{~N} / \mathrm{kg})$ than the WG $(26.54 \pm 1.98 \mathrm{~N} / \mathrm{kg})$ in the IMTP $(P=.01 ; \mathrm{ES}=2.6)$. In regard to $\mathrm{SJ}$ height, there were significant differences observed between the SG $(0.41 \pm 0.06)$ and the WG $(0.36$ $\pm 0.04 ; P=.03 ; \mathrm{ES}=0.9)$. Likewise, the $\mathrm{SG}$ produced significantly greater CMJ heights than the WG (SG 0.42 \pm 0.06 ; WG $0.37 \pm 0.04$; $P=.02 ; \mathrm{ES}=1.0)$. Stronger athletes demonstrated significantly lower sprint times in 5- $(P=.01$; ES $=1.1)$, and $10-\mathrm{m}(P=.01$; $\mathrm{ES}=1.2)$ than WG. The SG also demonstrated significantly lower CoDS times during $505 \mathrm{~L}(P=.01 ; \mathrm{ES}=1.2)$ and $505 \mathrm{R}(P=.01$; $\mathrm{ES}=1.7)$ than the WG.

\section{Discussion}

The aims of this study were to determine the relationships between maximal isometric strength, $\mathrm{VJ}$, sprint, and CoDS in academy netball players and to discover whether players who have high performance in isometric strength testing would demonstrate superior performance in VJ, sprint, and CoDS measures. The primary findings are that relative isometric strength and VJ performance have moderate to very large associations with sprint and CoDS and stronger players were able to produce significantly faster sprint and CoDS times and greater VJ heights than weaker players. These findings suggest that relative isometric strength could be a fundamentally important mechanism underpinning VJ, sprint, and CoDS performance.

In this study, IMTP PF demonstrated significant inverse correlations to $505 \mathrm{R}$ times $(r=-.66 ; P=.01)$. Similarly, Spiteri et $\mathrm{al}^{2}$ recently reported strong correlations $(r=-.79)$ between IMTP PF and 505 CoDS in elite female basketball athletes. In line with previ-

Table 1 Descriptive Statistics and Reliability for IMTP, Vertical-Jump, Sprint, and CoDS Variables

\begin{tabular}{lcccc}
\hline Reliability variable & Mean \pm SD & ICC (90\% Cl) & TE (90\% Cl) & CV\% (90\% CI) \\
\hline IMTP peak force (N/kg) & $30.70 \pm 5.26$ & $.91(.85-.95)$ & $1.55(1.31-1.91)$ & $5.3(4.5-6.6)$ \\
Squat jump (m) & $0.39 \pm 0.06$ & $.95(.92-.97)$ & $1.26(1.07-1.55)$ & $3.5(2.9-4.3)$ \\
Countermovement jump (m) & $0.39 \pm 0.05$ & $.94(.89-.97)$ & $1.24(1.05-1.53)$ & $3.5(2.9-4.3)$ \\
Sprint and CoDS & & & & \\
$\quad 5 \mathrm{~m}(\mathrm{~s})$ & $1.10 \pm 0.06$ & $.79(.63-.90)$ & $0.05(0.04-0.06)$ & $2.9(2.4-3.8)$ \\
$\quad 10 \mathrm{~m}(\mathrm{~s})$ & $1.88 \pm 0.09$ & $.74(.59-.85)$ & $0.04(0.04-0.05)$ & $2.2(1.8-2.7)$ \\
505 left (s) & $2.40 \pm 0.12$ & $.82(.63-.92)$ & $0.06(0.05-0.08)$ & $2.5(2.0-3.5)$ \\
505 right (s) & $2.37 \pm 0.10$ & $.77(.59-.87)$ & $0.05(0.04-0.07)$ & $2.1(1.7-2.8)$ \\
\hline
\end{tabular}

Abbreviations: IMTP, isometric midthigh pull; CoDS, change-of-direction speed; ICC, intraclass correlation coefficient; CI, confidence interval; TE, typical error; $\mathrm{CV}$, coefficient of variation. 
ous research, ${ }^{2,3,11}$ the results of this study illustrate the association of high levels of strength with enhanced CoDS performance in youth netball players, with relatively stronger players demonstrating faster CoDS times than weaker players (Table 4). Furthermore, it has also been reported that traditional, eccentric, and plyometric resistancetraining modalities result in large CoDS improvements, potentially due to the eccentric-concentric coupling action during the contact phase of CoDS tasks. ${ }^{6,25}$ It should be noted that the biomechanical demands of CoDS are dependent on angle ${ }^{26,27}$ and entry velocity ${ }^{28}$; therefore our findings are only applicable to a high-velocity $180^{\circ}$ turn task. Taking these results together, these findings suggest that the ability to change direction quickly highly depends on an athlete's ability to absorb and produce high levels of force rapidly.

The findings of this study demonstrate the importance of relative strength measures in relation to 5-m-sprint performance in youth

Table 2 Correlations Between IMTP, Vertical-Jump, Sprint, and CoDS Variables

\begin{tabular}{lcc}
\hline & $\mathbf{5 0 5} \mathbf{~ L ~ ( s ) ~}$ & $\mathbf{5 0 5} \mathbf{R}(\mathbf{s})$ \\
\hline IMTP peak force $(\mathrm{N} / \mathrm{kg})$ & -.48 & $-.66^{* *}$ \\
Squat jump (m) & $-.71^{* *}$ & $-.70^{* *}$ \\
Countermovement jump (m) & $-.71^{* *}$ & $-.60^{* *}$ \\
$5 \mathrm{~m}(\mathrm{~s})$ & .25 & .30 \\
$10 \mathrm{~m}(\mathrm{~s})$ & $.53^{*}$ & $.58^{*}$ \\
\hline
\end{tabular}

Abbreviations: IMTP, isometric midthigh pull; CoDS, change-of-direction speed; $\mathrm{L}$, left leg; R, right leg.

$* P \leq .05 . * * P \leq .01$.

Table 3 Correlations Between Isometric Midthigh-Pull, Vertical-Jump, and Sprint Variables

\begin{tabular}{lcc}
\hline & $\mathbf{5 ~ \mathbf { ~ m ~ ( s ) ~ }}$ & $\mathbf{1 0 ~ \mathbf { ~ }} \mathbf{( s )}$ \\
\hline Isometric midthigh-pull peak force $(\mathrm{N} / \mathrm{kg})$ & $-.49^{*}$ & -.41 \\
Squat jump $(\mathrm{m})$ & -.15 & $-.60^{* *}$ \\
Countermovement jump (m) & -.13 & $-.65^{* *}$ \\
\hline
\end{tabular}

$* P \leq .05$. ** $P \leq .01$. netball players. Similarly, McBride et $\mathrm{al}^{29}$ demonstrated a significant relationship ( $r=-.54 ; P=.02)$ between relative strength measured in the back squat and sprint performance $(10$ yards $[\sim 9 \mathrm{~m}])$ in college football players with a high relative strength $(\geq 2.1 \mathrm{~kg} / \mathrm{kg})$ compared with college football players with a lower relative strength $(<1.9$ $\mathrm{kg} / \mathrm{kg}$ ). These results are likely attributable to sprinting's requiring high levels of acceleration and strength to overcome the inertia of the body mass. Furthermore, faster sprint performers are shown to apply greater ground-reaction forces during shorter groundcontact times. ${ }^{30}$ These results seem to be consistent with research by Comfort et $\mathrm{al}^{31}$ that found that increases in relative strength were accompanied by improvements in sprint performance, with similar findings also reported in youth soccer players. ${ }^{12,32}$ It can thus be suggested that maximal strength and speed development should be emphasized as part of a periodized training program, ensuring appropriate development of each component dependent on the athletes' specific needs. Furthermore, given the strong relationship between IMTP PF and maximal dynamic strength, ${ }^{1}$ it is advocated that dynamic strength training be performed to train different strength and power capacities, whereas the IMTP can be used as a potential alternative to traditional 1-repetition-maximum testing.

This study highlights strong relationships between $\mathrm{VJ}$ and sprint performance that were similar to those previously reported in male adult athletes. ${ }^{33} \mathrm{VJ}$ height showed a stronger relationship with 10 -m-sprint performance ( $r=-.60$ to -.65 ) than with 5 -m-sprint performance $(r=-.13$ to -.15$)$. In contrast to our findings, Nimphius et $\mathrm{al}^{34}$ failed to find a significant relationship between $\mathrm{VJ}$ height and sprint performance in female softball players. Possible reasons for different findings may be the differing requirements of the sports or the smaller sample size. For example, VJ performance is not as essential for softball-skills practice or performance, whereas jumping is a more common aspect of netball performance and training. In addition, as VJ performance has been found to be a reliable predictor of success in several sports, netball athletes are probably more homogeneous in VJ performance, which may explain the stronger correlation. Finally, although jump mats provide a valid measurement of jump height, ${ }^{35}$ the use of the flight-time method may overestimate jump height compared with the velocity-at-takeoff method derived from force platforms. ${ }^{36}$ However, jump mats can provide practical data that can positively affect training and performance. Therefore, it is suggested that readers take into account the method used to calculate jump height and the reported values when interpreting the findings of the current study.

Table 4 Comparison Between Stronger and Weaker Athletes in IMTP, Vertical Jump, Sprint, and Change-of-Direction Speed

\begin{tabular}{|c|c|c|c|c|c|}
\hline & Strong $(n=13)$, mean \pm SD & Weak $(n=13)$, mean \pm SD & $\boldsymbol{P}$ & ES & Difference \\
\hline Body mass $(\mathrm{kg})$ & $65.54 \pm 6.90$ & $66.54 \pm 7.82$ & .732 & 0.1 & $-1.5 \%$ \\
\hline IMTP peak force $(\mathrm{N} / \mathrm{kg})$ & $34.86 \pm 4.02$ & $26.54 \pm 1.98$ & .001 & 2.6 & $23.9 \%$ \\
\hline Squat jump (m) & $0.41 \pm 0.06$ & $0.36 \pm 0.04$ & .032 & 0.9 & $11.4 \%$ \\
\hline Countermovement jump (m) & $0.42 \pm 0.05$ & $0.37 \pm 0.04$ & .024 & 1.0 & $10.3 \%$ \\
\hline \multicolumn{6}{|c|}{ Sprint and change-of-direction speed } \\
\hline $5 \mathrm{~m}(\mathrm{~s})$ & $1.08 \pm 0.06$ & $1.15 \pm 0.05$ & .010 & 1.1 & $-6.0 \%$ \\
\hline $10 \mathrm{~m}(\mathrm{~s})$ & $1.91 \pm 0.06$ & $1.99 \pm 0.06$ & .006 & 1.2 & $-3.7 \%$ \\
\hline 505 left (s) & $2.44 \pm 0.08$ & $2.55 \pm 0.11$ & .007 & 1.2 & $-4.5 \%$ \\
\hline 505 right (s) & $2.41 \pm 0.08$ & $2.54 \pm 0.07$ & .001 & 1.7 & $-5.2 \%$ \\
\hline
\end{tabular}

Abbreviations: IMTP, isometric midthigh pull; ES, effect size. 
Our findings revealed large to very large associations $(r=-.60$ to -.71 ) between $\mathrm{VJ}$ height and $505 \mathrm{CoDS}$ performance, suggesting both slow and fast reactive strength to be highly related to CoDS. Previous research demonstrates contact times of final turns during CoDS to be approximately $>0.4$ second, whereas movement times during CMJ are approximately 0.5 second $^{37}$ and thus may be more likened to CoDS contact times. In addition, the observed findings may be due to the specific CoDS tests used in the research studies. Previous research demonstrates similar relationships between VJ and CoDS when using a single change in direction. ${ }^{16,33}$ In addition, the 505 test may be heavily influenced by linear-sprinting ability during the 15-m approach, rather than change-of-direction ability, given the significant relationships between 10-m-sprint performance and CoDS found in the current study ( $r=-.53$ to -.58$)$.

Although the SG and WG did not differ in terms of body mass, the SG had superior lower-body maximal isometric strength $(P=$ .01 ; ES = 2.6). Increased relative strength would be advantageous in a sport such as netball, where VJ, sprinting, and CoDS involve high levels of force production and absorption to overcome the inertia of body mass. These results support the association between maximal strength and dynamic performance given the significant differences between the SG and WG in VJ (ES = 0.9-1.0), sprint (ES $=1.1-1.2)$, and CoDS (ES = 1.2-1.7). These findings suggest that maximum strength is an important aspect of physical preparation for netball players. It could be speculated that traditional strength exercises (squats, dead lifts, and Olympic lifts) have an important role to play in the physical preparation of netball players; however, this is not a common training practice of the majority of youth netball players. Despite the promising results of resistance training in youth athletes, ${ }^{12,13,32}$ further longitudinal studies are needed to confirm this present assumption.

\section{Practical Applications}

The results of this study illustrate the importance of developing high levels of lower-body strength to enhance VJ, sprint, and CoDS performance in youth netball players. Furthermore, stronger athletes demonstrated superior VJ, sprint, and CoDS performances. Team coaches and strength and conditioning coaches should ensure that youth netball players develop maximal strength in a periodized manner, which should result in improvements in VJ, sprint, and CoDS performance. Specifically, training programs aimed toward the enhancement of maximal concentric and eccentric strength may potentially enhance the performance of dynamic movements involving high levels of force production and absorption.

\section{Conclusions}

In conclusion, the current study found that the group with greater IMTP PF also had superior VJ, sprint, and CoDS performance. There were significant correlations between the IMTP PF and sprint and CoDS performance. Furthermore, CoDS was found to be related to the jump heights of both SJ and CMJ.

\section{References}

1. McGuigan MR, Winchester JB. The relationship between isometric and dynamic strength in college football players. J Sports Sci Med. 2008;7:101-105. PubMed
2. Spiteri T, Nimphius S, Hart NH, Specos C, Sheppard JM, Newton RU. Contribution of strength characteristics to change of direction and agility performance in female basketball athletes. $J$ Strength Cond Res. 2014;28(9):2415-2423. PubMed doi:10.1519/ JSC.0000000000000547

3. Thomas C, Comfort P, Chiang C, Jones PA. Relationship between isometric mid-thigh pull variables and sprint and change of direction performance in collegiate athletes. J Trainol. 2015;4(1):6-10. http:// dx.doi.org/10.17338/trainology.4.1_6

4. West DJ, Owen NJ, Jones MR, et al. Relationships between force-time characteristics of the isometric midthigh pull and dynamic performance in professional rugby league players. $J$ Strength Cond Res. 2011;25(11):3070-3075. PubMed doi:10.1519/ JSC.0b013e318212dcd5

5. Kraska JM, Ramsey MW, Haff GG, et al. Relationship between strength characteristics and unweighted and weighted vertical jump height. Int J Sports Physiol Perform. 2009;4(4):461-473. PubMed doi:10.1123/ijspp.4.4.461

6. Spiteri T, Cochrane JL, Hart NH, Haff GG, Nimphius S. Effect of strength on plant foot kinetics and kinematics during a change of direction task. Eur J Sport Sci. 2013;13(6):646-652. PubMed doi:10 $.1080 / 17461391.2013 .774053$

7. Abe T, Kawakami Y, Ikegawa S, Kanehisa H, Fukunaga T. Isometric and isokinetic knee joint performance in Japanese alpine ski racers. The Journal of sports medicine and physical fitness. 12/ 1992;32(4):353-357.

8. Thomas C, Jones PA, Comfort P. Reliability of the Dynamic Strength Index in collegiate athletes. Int J Sports Physiol Perform. 2015;10(5):542-545. PubMed doi:10.1123/ijspp.2014-0255

9. Fox A, Spittle M, Otago L, Saunders N. Activity profiles of the Australian female netball team players during international competition: implications for training practice. J Sports Sci. 2013/10/01 2013;31(14):1588-1595.

10. Hewit J, Cronin J, Button C, Hume P. Understanding deceleration in sport. Strength Cond J. 2011;33(1):47-52. doi:10.1519/ SSC.0b013e3181fbd62c

11. Spiteri T, Newton RU, Binetti M, Hart NH, Sheppard JM, Nimphius S. Mechanical determinants of faster change of direction and agility performance in female basketball athletes. $J$ Strength Cond Res. 2015;29(8):2205-2214. PubMed doi:10.1519/ JSC.0000000000000876

12. Chelly MS, Fathloun M, Cherif N, Amar MB, Tabka Z, Van Praagh E. Effects of a back squat training program on leg power, jump, and sprint performances in junior soccer players. J Strength Cond Res. 2009;23(8):2241-2249. PubMed doi:10.1519/JSC.0b013e3181b86c40

13. Keiner M, Sander A, Wirth K, Schmidtbleicher D. Long-term strength training effects on change-of-direction sprint performance. J Strength Cond Res. 2014;28(1):223-231. PubMed doi:10.1519/ JSC.0b013e318295644b

14. Comfort P, Stewart A, Bloom L, Clarkson B. Relationships between strength, sprint, and jump performance in well-trained youth soccer players. J Strength Cond Res. 2014;28(1):173-177. PubMed doi:10.1519/JSC.0b013e318291b8c7

15. Peterson MD, Alvar BA, Rhea MR. The contribution of maximal force production to explosive movement among young collegiate athletes. J Strength Cond Res. 2006;20(4):867-873. PubMed

16. Jones P, Bampouras T, Marrin K. An investigation into the physical determinants of change of direction speed. J Sports Med Phys Fitness. 2009;49(1):97-104. PubMed

17. Comfort P, Jones PA, McMahon JJ, Newton R. Effect of knee and trunk angle on kinetic variables during the isometric midthigh pull: 
test-retest reliability. Int J Sports Physiol Perform. 2015;10(1):58-63. PubMed https://doi.org/10.1123/ijspp.2014-0077

18. Stone MH, Sands WA, Carlock J, et al. The importance of isometric maximum strength and peak rate-of-force development in sprint cycling. J Strength Cond Res. 2004;18(4):878-884. PubMed

19. McMahon JJ, Jones PA, Comfort P. A correction equation for jump height measured using the Just Jump System. Int J Sports Physiol Perform. 2016;11(4):555-557. PubMed https://doi.org/10.1123/ ijspp.2015-0194

20. Hopkins W. Reliability from consecutive pairs of trials (Excel spreadsheet). A new view of statistics. 2000. Sportscience

21. Hopkins WG. Measures of reliability in sports medicine and science. Sports Med. 2000;30(1):1-15. PubMed doi:10.2165/00007256200030010-00001

22. Curtin F, Schulz P. Multiple correlations and Bonferroni's correction. Biol Psychiatry. 1998;44(8):775-777. PubMed doi:10.1016/S00063223(98)00043-2

23. Hopkins WG. A scale of magnitudes for effect statistics. A new view of statistics. Sportscience. 2002. http://sportsci.org/resource/stats/ effectmag.html.

24. Cohen J. Statistical Power Analysis for the Behavioral Sciences. Hillsdale, NJ: Lawrence Erlbaum; 1988.

25. Plisk SS. Speed, agility, and speed endurance development. In: Baechle TR, Earle RW, eds. Essentials of Strength Training and Conditioning. 2nd ed. Champaign, IL: Human Kinetics; 2000:471-491.

26. Havens KL, Sigward SM. Whole body mechanics differ among running and cutting maneuvers in skilled athletes. Gait Posture. 9// 2015;42(3):240-245. doi:10.1016/j.gaitpost.2014.07.022

27. Havens KL, Sigward SM. Cutting mechanics: relation to performance and anterior cruciate ligament injury risk. Med. Sci. Sports Exerc. 2015;47(4):818-824. doi:10.1249/MSS.0000000000000470

28. Vanrenterghem J, Venables E, Pataky T, Robinson MA. The effect of running speed on knee mechanical loading in females during side cutting. J Biomech. 2012;45(14):2444-2449. PubMed doi:10.1016/j. jbiomech.2012.06.029
29. McBride JM, Blow D, Kirby TJ, Haines TL, Dayne AM, Triplett NT. Relationship between maximal squat strength and five, ten, and forty yard sprint times. J Strength Cond Res. 2009;23(6):1633-1636. PubMed doi:10.1519/JSC.0b013e3181b2b8aa

30. Hunter JP, Marshall RN, McNair PJ. Relationships between ground reaction force impulse and kinematics of sprint-running acceleration. J Appl Biomech. 2005;21(1):31-43. PubMed doi:10.1123/jab.21.1.31

31. Comfort P, Haigh A, Matthews MJ. Are changes in maximal squat strength during preseason training reflected in changes in sprint performance in rugby league players? J Strength Cond Res. 2012;26(3):772776. PubMed doi:10.1519/JSC.0b013e31822a5cbf

32. Christou M, Smilios I, Sotiropoulos K, Volaklis K, Pilianidis T, Tokmakidis SP. Effects of resistance training on the physical capacities of adolescent soccer players. J Strength Cond Res. 2006;20(4):783-791. PubMed

33. Hori N, Newton RU, Andrews WA, Kawamori N, McGuigan MR, Nosaka K. Does performance of hang power clean differentiate performance of jumping, sprinting, and changing of direction? $J$ Strength Cond Res. 2008;22(2):412-418. PubMed doi:10.1519/ JSC.0b013e318166052b

34. Nimphius S, McGuigan MR, Newton RU. Relationship between strength, power, speed, and change of direction performance of female softball players. J Strength Cond Res. 2010;24(4):885-895. PubMed doi:10.1519/JSC.0b013e3181d4d41d

35. Leard JS, Cirillo MA, Katsnelson E, et al. Validity of two alternative systems for measuring vertical jump height. J Strength Cond Res. 2007;21(4):1296-1299. PubMed

36. Moir GL. Three different methods of calculating vertical jump height from force platform data in men and women. Measurement in Physical Education and Exercise Science. 2008/10/14 2008;12(4):207-218. doi:10.1080/10913670802349766

37. Gathercole R, Sporer B, Stellingwerff T, Sleivert G. Alternative countermovement-jump analysis to quantify acute neuromuscular fatigue. Int J Sports Physiol Perform. 2015;10(1):84-92. PubMed doi:10.1123/ijspp.2013-0413 